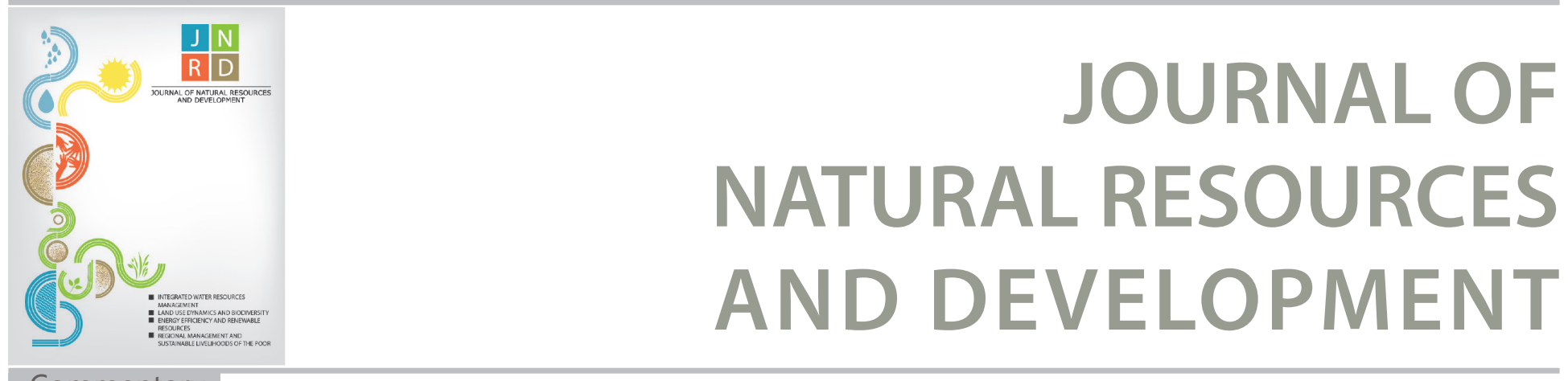

\title{
New focus of environmental education programs
}

\author{
Alexander Neaman ${ }^{a^{*}}$ and Andrés Mariób \\ aÁrea del Medio Ambiente, Facultad de Agronomía, Pontificia Universidad Católica de Valparaíso, Quillota, Chile

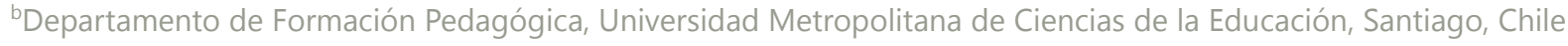 \\ * Correspondence: E-mail: alexander.neaman@ucv.cl, Fax: +56-32-2274570
}

\section{Does environmental knowledge determines pro-environmental behavior?}

Humanity is currently facing various global environmental problems including climate change, ecosystem destruction, loss of biodiversity, soil erosion, decreased natural food resources, and a limited availability of energy and fresh water, among others (Diamond, 2011). In our opinion, the ultimate goal of environmental education is to achieve pro-environmental behavior of the population, i.e. environmentally friendly behavior. It is often believed that increased environmental knowledge leads to pro-environmental behavior, i.e. environmentally friendly behavior. For instance, Plotnikoff et al. (2008) suggest that the mass media should provide more information to encourage the population to make changes in their environmental behavior. Indeed, widespread publicity campaigns have been dedicated to environmental topics in various mass communication media, documentary films, and magazines with the objective of creating environmental awareness throughout society, in hopes that everyone would learn about these issues and take positive environmental actions.

The opinion that increased environmental knowledge leads to pro-environmental behavior is disputed. For example, in their seminal paper in the field of environmental education, Hungerford and Volk (1990) demonstrated that knowledge does not lead to behavior change in the environmental dimension. Heimlich (2010) came to the same conclusion. In particular, Kellstedt et al. (2008) showed that the more informed one is about global warming, the less one feels personally responsible for the problem and becomes concerned about global warming. In other words, the research shows that the more actively the media publicizes the problem and the more informed people are, the less concerned about it individuals become. Similarly, Tal (2010) demonstrated that environmental education improved the knowledge of university students; however, there were few behavior changes with respect to the environment. On the other hand, several other studies have found weak relationships between environmental knowledge and behavior. The amount of behavioral variance that can be explained by environmental knowledge varies between $6 \%$ and $18 \%$ (Barazarte et al., in press, Frick et al., 2004, Geiger et al., in press).

\section{Integral environmental education}

Some researchers emphasized that altruistic, egoistic and biospheric values influence pro-environmental behavior (for instance, Clark et al., 2003). Specifically, it is assumed that altruistic, egoistic and biospheric values influence pro-environmental beliefs (or considerations), which in turn influence pro-environmental intentions and behavior (de Groot \& Steg, 2009). There are also empirical finding that prosociality, i.e. sensitive dealing with others, is highly related to pro-environmental behavior (Kaiser \& Byrka, 2011). Similarly, it is demonstrated that egoistic environmental concerns, i.e. concerns to the self in relation to the environment, are related to our egoistic relationship to each other (Isaac et al., 2012, Laitman \& Ulianov, 2012). The latter authors consider that we cannot really try to correct our dealings with the environment while ignoring our dealings with each other. They suggest that we must educate people to become sensitive toward others, which in turn will make 
them being responsible in their approach to the environment. In our opinion, such an approach could be called "integral environmental education".

\section{From "saving the environment" to "humans are an integral part of nature"}

It is important to analyze the current focus of our environmental education programs and to suggest a possible new focus. Environmental education programs often divide the world between "humans" and "environment". This division makes us think that the environment is a supplement to humanity. Most likely, this disconnection with nature is the cause of inefficiency of informal environmental education. Therefore, it is important to understand principles of natural systems and focus our environmental programs according to these principles.

Perhaps the most important principle of natural systems is interconnectedness and interdependence of all their parts. Many researchers emphasize the importance of this principle in natural systems (for instance, Harman \& Sahtouris, 1998, Sahtouris \& Lovelock, 2000). The human body is an example of such an interconnected and interdependent system. Within our bodies, the homeostasis among all cells and organs enable the body to maintain proper health. To remain healthy, each cell and organ operates according to the interests of the entire organism. Social scientists also recognize the principle of interconnectedness (for instance, Christakis \& Fowler, 2010). In consequence, we should change the focus of our environmental education programs. The focus on "saving the environment" should be replaced with a focus on "humans are an integral part of nature".

\section{References}

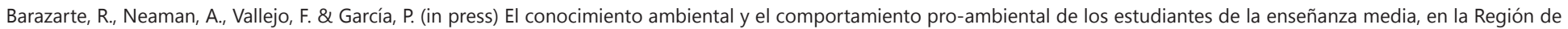
Valparaíso (Chile). Revista de Educación.

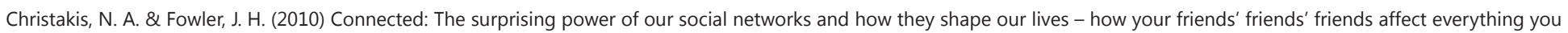
feel, think, and do (New York, NY, USA, Little, Brown and Company).

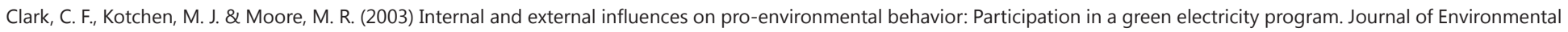
Psychology, 23, 237-246.

De Groot, J. I. M. \& Steg, L. (2009) Mean or green: Which values can promote stable pro-environmental behavior? Conservation Letters, 2, $61-66$.

Diamond, J. (2011) Collapse: How Societies Choose to Fail or Succeed. Revised edition (London, UK, Penguin Group).

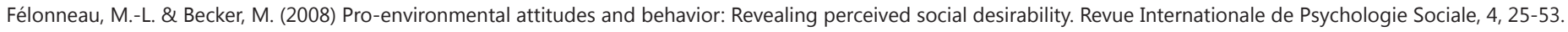

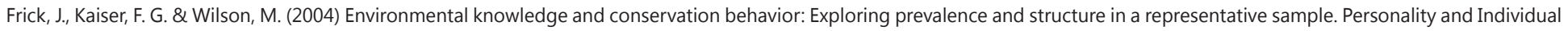
Differences, 37, 1597-1613.

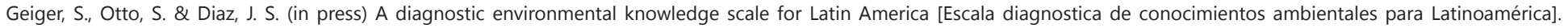
Psyecology.

Harman, W. \& Sahtouris, E. (1998) Biology revisioned (Berkeley, CA, USA, North Atlantic Books).

Heimlich, J. E. (2010) Environmental education evaluation: Reinterpreting education as a strategy for meeting mission. Evaluation and Program Planning, $33,180-185$.

Hungerford, H. \& Volk, T. (1990) Changing learner behavior through environmental education. Journal of Environmental Education, $21,8-21$.

Isaac, G., Levy, J. \& Ognits, A. (2012) The benefits of the new economy. (Toronto, ON, Canada, ARI Publishers, www.ariresearch.org).

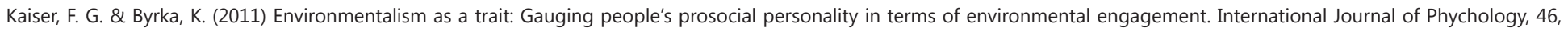
71-79.

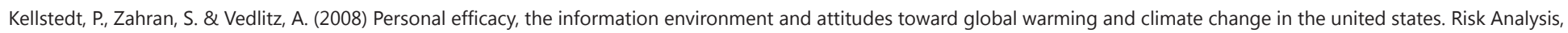
28, 1-14.

Laitman, M. \& Ulianov, A. (2012) A guide to the new world (Toronto, ON, Canada, ARI Publishers, www.ariresearch.org).

Sahtouris, E. \& Lovelock, J. E. (2000) Earthdance: Living systems in evolution (Lincoln, NE, USA, iUniversity Press).

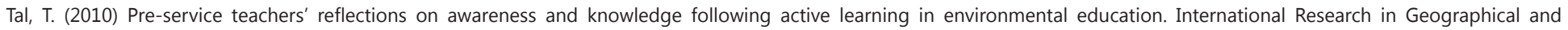
Environmental Education, 19, 263-276. 